\title{
Stability of Bioactive Extracts from Porphyridium purpureum Microalgae Biomass under Various Stress Factors ${ }^{\dagger}$
}

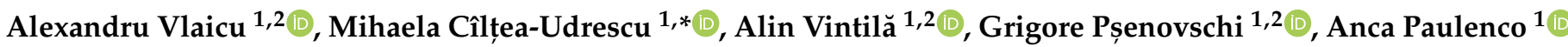 \\ and Ana-Maria Gălan ${ }^{1}$ \\ 1 National Institute for Research \& Development in Chemistry and Petrochemistry-ICECHIM, \\ 060021 Bucharest, Romania; alexvlaicu16@yahoo.co.uk (A.V.); vintila_alin_94@yahoo.com (A.V.); \\ gregorypshenovschi@gmail.com (G.P.); ancapaulenco@gmail.com (A.P.); \\ anamariagalan88@gmail.com (A.-M.G.) \\ 2 Faculty of Applied Chemistry and Materials Science, University Politehnica of Bucharest, \\ 060042 Bucharest, Romania \\ * Correspondence: mihaela.ciltea.udrescu@gmail.com \\ + Presented at the 17th International Symposium "Priorities of Chemistry for a Sustainable Development" \\ PRIOCHEM, Bucharest, Romania, 27-29 October 2021.
}

Keywords: Porphyridium purpureum; bioactive extracts; stability; stress factors

Citation: Vlaicu, A.; Cîlțea-Udrescu, M.; Vintilă, A.; Pșenovschi, G.; Paulenco, A.; Gălan, A.-M. Stability of Bioactive Extracts from Porphyridium purpureum Microalgae Biomass under Various Stress Factors. Chem. Proc. 2022, 7, 13. https:// $10.3390 /$ chemproc2022007013

Academic Editors: Mihaela Doni, Florin Oancea, Zina Vuluga and Radu Claudiu Fierăscu

Published: 28 February 2022

Publisher's Note: MDPI stays neutral with regard to jurisdictional claims in published maps and institutional affiliations.

Copyright: (C) 2022 by the authors. Licensee MDPI, Basel, Switzerland. This article is an open access article distributed under the terms and conditions of the Creative Commons Attribution (CC BY) license (https:// creativecommons.org/licenses/by/ $4.0 /)$.

\section{Introduction}

Nowadays, the interest for high-quality products of natural origin is increasing worldwide. Algae derived products have been recognized to have great potential as a rich source of bioactive compounds and their importance is growing rapidly. The bioactive compounds contained in algae extracts are proteins, unsaturated fatty acids, antioxidants (polyphenols, vitamin E, vitamin C) and other pigments (phycobiliproteins, carotenoids and chlorophylls). Such bioactive compounds have antibacterial, anti-inflammatory, antiviral, antifungal and antioxidative properties, with numerous health benefits. Algal extracts are widely used as biostimulants, bioregulators, nutritional supplements, pharmaceutical, food and cosmetics colorants [1]. The present study investigates the stability of bioactive extracts obtained from Porphyridium purpureum microalgae biomass subjected to a series of stress factors generated by exposure to a light source for different time intervals and at different temperatures.

\section{Materials and Methods}

Experiments were performed using Porphyridium purpureum microalgae strain from ICECHIM's strain collection, inoculated in its specific growth medium, ASW (artificial sea water). After cultivation, microalgae biomass was harvested, dried and grinded for more efficient processing. Extractions of bioactive compounds from Porphyridium purpureum powder were obtained using different solvents. For the phycobiliproteins extracts, a sodium phosphate buffer solution with a $\mathrm{pH}$ value of 6.8 , was used, while for the chlorophylls and carotenoids extracts, the proposed solvents were acetone, methanol and ethanol. Various exposure times between $3 \mathrm{~h}$ and $40 \mathrm{~h}$, at a light source with an intensity of $36.5 \mu \mathrm{moli} \cdot \mathrm{m}^{-2} \mathrm{~s}^{-1}$ and temperatures between $30^{\circ} \mathrm{C}$ and $70^{\circ} \mathrm{C}$ were used. To observe and compare the stability of the extracts, the absorbances of the samples were measured spectrophotometrically at wavelengths specific to the biocompound monitored, before and after applying the stress factors.

\section{Results}

It was observed, in the case of the chlorophylls and carotenoids extract, that the presence of a light source played a more significant role on the stability of biocompounds, with up to $90 \%$ degradation after $40 \mathrm{~h}$ of exposure, no matter which extraction solvent was 
used, with chlorophyll a being the most abundant pigment and at the same time the most vulnerable to degradation as a result of light exposure. In the case of using temperature as a stress factor, it was observed that for a lower temperature, of about $40{ }^{\circ} \mathrm{C}$, the concentrations of both chlorophyll and phycobiliproteins extracts were reduced by a maximum of $20 \%$, but when a higher temperature of $70{ }^{\circ} \mathrm{C}$ was proposed for the phycobiliproteins extract, a few minutes of exposure to this stress factor were sufficient to reach almost complete degradation of biocompounds.

\section{Conclusions}

Studies were carried out for the obtained sample of solvent containing the bioactive compounds, in order to evaluate their stability in different stress conditions. Light stress proved to be a more important factor for the stability of chlorophylls, while high temperatures led to faster degradation of phycobiliproteins.

Author Contributions: A.V. (Alin Vintila) and G.P. were responsible for the growth and harvesting of microalgae used in these experiments, M.C.-U. and A.V. (Alexandru Vlaicu) were responsible for obtaining and evaluating the stability of microalgae extracts, data processing and analysis, A.P. and A.-M.G. were responsible for supervising the experiments and writing the manuscript. All authors have read and agreed to the published version of the manuscript.

Funding: This work was supported by a grant of the Romanian Ministry of Education and Research, project number PN 19.23.01.01, and a grant of UEFISCDI, project number PN-III-P1-1.1-TE-2019-1842, within PNCDI III.

Institutional Review Board Statement: Not applicable.

Informed Consent Statement: Not applicable.

Data Availability Statement: Not applicable.

Conflicts of Interest: The authors declare no conflict of interest.

\section{Reference}

1. Bule, M.H.; Ahmed, I.; Maqbool, F.; Bilal, M.; Iqbal, H.M. Microalgae as a source of high-value bioactive compounds. Front. Biosci. 2018, 10, 197-216. 